\title{
STUDENT INTERACTION WITH THE INTERPLAY TOOL
}

\author{
Jose G. Rios ${ }^{1}$, Eloina Garcia ${ }^{1}$, Isabel Martón ${ }^{2}$ \\ ${ }^{1}$ Universitat Politècnica de València. Instituto de Ciencias de la Educación (SPAIN) \\ ${ }^{2}$ Universitat Poltècnica de València. Departamento de Estadística, Investigación Operativa \\ Aplicadas y Calidad (SPAIN) \\ jorioli@ice.upv.es, eloina.garcia@ice.upv.es, ismarllu@upv.es
}

\begin{abstract}
Among the priorities of the Polytechnic University of Valencia's Education Science Institute (ICE in Spanish) is the training of university teachers, in which one of the subjects covered is the development and application of technological resources to improve the teaching-learning process.

The ICE's Educational and Multimedia Resources Bureau (GREM in Spanish) has developed the InterPLAY teaching tool to promote changes that make it necessary to re-invent the teaching process, in which the teachers take on an innovative role and create conditions for the students to acquire new knowledge, experience and elements that generate analytical, reflective and acquisition processes.

Apart from being a teaching video, InterPLAY allows the teacher to introduce information (recordings, videos, questions, images, files, graphs, embedded web pages, etc) and construct it in a way to suit teaching criteria, facilitate the students' learning, and especially generate interaction with the contents. There are clear standards for the correct use of the teaching resource in the subject [2]. It must be relevant, up-to-date and realistic, as well as have high image and audio quality, and of course assist in learning the contents to be studied. Both its design and production, the resource's foundation, and experimentation and evaluation are creatively and dynamically inserted into the teaching-learning process and can be used as a tool to develop competencies and skills in the students, who are benefitted by playing a more active learning role, making education more accessible and dynamic [3],

This paper describes the characteristics of the practical formative sessions, which use an experiential method for teachers to learn to design their own teaching resources using InterPLAY [4]. The participants were teachers who give different engineering degree subjects, including master's degree courses. We also give an analysis of the evaluations given in the participants' responses to the questionnaire specially composed for this purpose at the end of the last two courses. These considered the evaluations as regards the didactic use of the tool, with an analysis of its impact on the learning process, its degree of interest, and the difficulties encountered in the tool's different applications, both from the teachers' and students' point of view. Using InterPLAY is a constant incentive for teachers to give more thought to their teaching methods.
\end{abstract}

Keywords: Innovation, technology, interactive, audiovisual.

\section{INTRODUCTION}

University teacher training is a priority of the work of the Polytechnic University of Valencia's Education Science Institute (ICE in Spanish), including the development and application of technological resources to improve the teaching-learning process.

Multimedia teaching support materials have proliferated in the last ten years as a new way of transmitting contents, but without giving the students a chance to "participate" and often without managing to gain the students' attention.

One of the aims of the UPV's Educational and Multimedia Resources Bureau (GREM in Spanish) is to contribute to designing tools to palliate these deficiencies and assist teachers with the support of resources they can apply in their classes to improve the students' learning.

The GREM coordinator, José Gabriel Ríos Lizana, (ICE audiovisual specialist) designed the InterPLAY teaching tool [4], independently of the UPV, the last link in a software system he designed integrally that allows the GREM service to be efficiently managed by a single operator. This system manages the entire production process of audiovisual materials, including user service requests to the automatic conversion and incorporation of the generated files, and the publication of the materials in online repositories. The novelty of InterPLAY is that it can add superimposed textual or graphic layers 
(SDK) in time, plus another layer of reproduction control (EDL), which permits interaction by means of menus and buttons to help the teacher to graphically plan on the video or audio itself how the student should follow the explanations they contain.

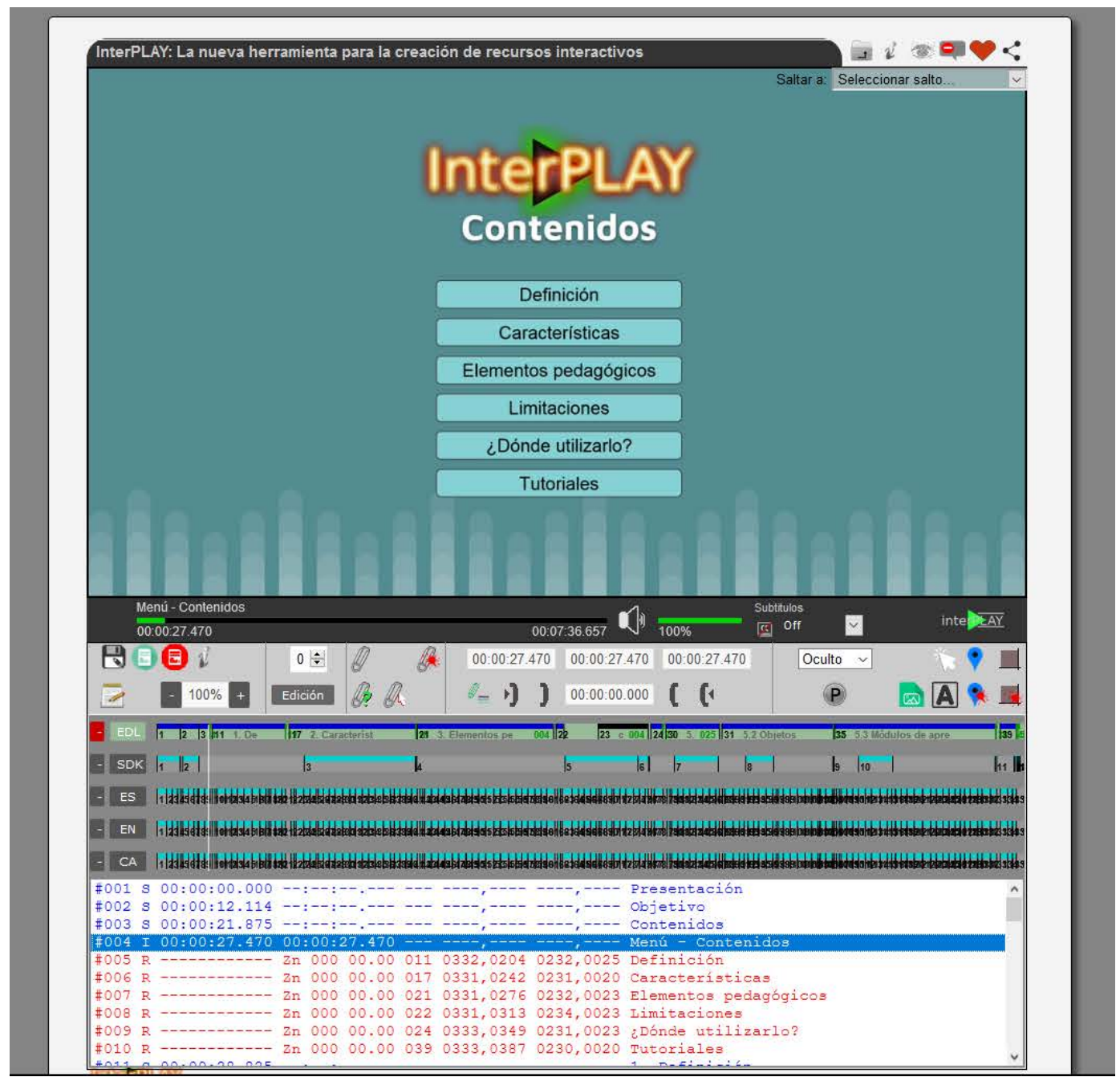

Figure 1. View of InterPLAY editor and its component parts (top to bottom): contents viewer, reproduction bar, tool bar, graphic tracks and text section.

\section{METHODOLOGY}

The ICE plans and coordinates the training of UPV teachers and offers different programs to satisfy the demands derived from the changes in the University in recent years. Integration into the European Higher Education Area, the implantation of the Online Teaching Plan, the development of the "Inverse Class" method and others have meant that teachers need to generate and produce an interminable amount of teaching materials adapted to the new characteristics of the students to make them more involved in their teaching.

The training offer includes a specific workshop for the didactic use of the InterPLAY tool by its creator, who, as the GREM coordinator has an important role not only in training teachers to use these tools, but also to give them technical assistance and teaching support for implanting innovations to improve the quality of the materials. The training consists of two 4-hour sessions in which the teachers learn to design their own resources using InterPLAY in which they are constrained to reflect on all the development phases and the implications for the students' learning. In other words, the training goes beyond the technical part and adds the pedagogical value of its different applications.

The session begins with seeing a video with InterPLAY implementing (https://grem.upv.es/Grem/ index.php?mnu=videoteca\&v=3231-sTXWDowuv4cA7UNYKv_Op_), which shows all the tool's possibilities and how it can be used for teaching, with links to other videos in Screencast and 
Polimedia Plus format. This gives them ideas on how they can prepare their materials when recording videos. It is a lively and up-to-date video, which InterPLAY facilitates, and also suggests links to additional material to add to the information already available. There is also a "Tutorials" section with links to other videos, which explains how the interactive layer has been developed and so learn how to use the tool. It also has a PDF file of an up-to-date user manual. In this way, their minds are opened to all the potential at their disposal in a single video, which they can keep as course material and for further consultations.

The video has two training functions: to give the students an idea of the tool's potential, and to serve as a guide or reference for practice, since the student has the same video but without the interactive InterPLAY layer. This is called the "Dummy InterPLAY" (https://grem.upv.es/Grem/ index.php? mnu=videoteca\&v=3232-NOgnDGF_iXQEW3uzX3xD70). With the help of the teacher and the tutorials the students can make their own interactive layer with the InterPLAY editor so that they can achieve identical results to the reference video. The "dummy" has special characteristics that consider all the users as its proprietors, so that they can accede to the InterPLAY editor to work, since only the proprietors can edit an InterPLAY project. The only condition is that the "dummy" cannot store the work in the server, but they can download their work files to their local device to send to the teacher if they have any doubts and upload them again to the editor to carry on practicing in a later session.

We give here the results of the special questionnaire answered by 20 of the 40 participating teachers at the end of the sessions. Some of the questions are closed while others are open. The teachers are in charge of various master's engineering degree subjects at the UPV. The evaluations of the tool's didactic use were considered and an analysis was made of their impact on learning, the degree of interest and the difficulties encountered in the tool's different applications, from both the teacher's and student's point of view. The teachers consider that using InterPLAY is a constant incentive to think about their teaching methods.

\section{RESULTS}

Below we give the results of the questionnaire on the INTERplay tool filled in by the teachers after the training sessions. First we give the analysis of the open questions by a qualitative method, followed by the results of closed questions by a graphic analysis.

\subsection{Qualitative analysis of university teachers' evaluations}

The qualitative section of the questionnaire was composed of four questions with the aim of collecting detailed information of the teachers' evaluations of the InterPLAY tool.

The first was on the tool's aim: "How can InterPLAY improve students' learning?

The second was more specific and aimed to determine if it could be applied to specific subjects: In which of your subjects could you use it? Why?

The third aimed to determine its advantages and disadvantages: Advantages and disadvantages of using InterPLAY?

And the fourth was: How would you recommend improving the tool to improve student learning and possible incorporation into the system?.

The qualitative analysis below presents the responses to each of the questions. The last was not considered since the recommendations given referred exclusively to the tool's technical aspects.

\subsubsection{InterPLAY improves students' learning}

The teachers highlighted different aspects that have a direct impact on learning. Most of them emphasized the interactive character InterPLAY gives to the video, "the possibility of pausing to interact with the video" offers many possibilities, "makes viewing it much more interesting" and "the didactic material becomes more attractive and doubtless encourages the students' interest".

Any tool that generates interacting improves learning "on capturing their attention" since it banishes monotony. It is easier to locate the material you are looking for if it is organized into sections, since InterPLAY can create content and learning sequencers.

Without any doubt it leads to deeper learning in which each student can "fill in the blanks in his knowledge", and can "can get a complete explanation or one adapted to his level at any time", 
"reinforce the subject's key contents", "do exercises and reflect on his degree of understanding and learning", revise any parts not fully understood, and do all this at any time that suits him.

They also emphasize the possibility of "evaluating their own achievements", learning fitted to suit each student's needs to see specific parts, it "allows them to check their own learning" and incorporate feedback, the student answers the question in real time. When he makes a mistake he can see an explanation to clarify his error and if he is right he can go on to the next point.

\subsubsection{Type of subjects suitable for InterPLAY}

Certain types of subject can facilitate the tool's application, either for their contents or methods, or can put up barriers to impede its use. The teachers, most of whom were engineers, give different types of subjects in different courses from ordinary degrees to a masters' degree, so that their evaluations respond to diverse teaching-learning experiences.

All the teachers considered that the tool could be used in their subjects and some even considered that it could be used in all of them, as can be seen at the end of Table 1, which shows the characteristics of each subject and how InterPLAY could be applied to it.

Table 1. Subjects to which InterPLAY could be applied.

\begin{tabular}{|c|c|c|}
\hline Subject & Characteristics & InterPLAY \\
\hline $\begin{array}{l}\text { Control of Chemi cal } \\
\text { Processes }\end{array}$ & $\begin{array}{l}\text { Very dense } \\
\text { Heterogeneous Learning Rate }\end{array}$ & $\begin{array}{l}\text { Students choose speed (level) of interactive videos } \\
\text { Reinforcement-Questions with feedback in real } \\
\text { time }\end{array}$ \\
\hline Descriptive Geometry & Detailed Drawings & $\begin{array}{l}\text { Superimpose many visual contents and links to } \\
\text { other resources with options to embed webs. }\end{array}$ \\
\hline English & $\begin{array}{l}\text { Audiovisual Material on Static } \\
\text { Platform }\end{array}$ & Interacts with students during activities. \\
\hline Building Subjects & Building Process Videos & $\begin{array}{l}\text { Highlight specific parts. } \\
\text { Divide the construction of a wall. } \\
\text { Links to building details. }\end{array}$ \\
\hline $\begin{array}{l}\text { Fauna Conservation } \\
\text { and Management }\end{array}$ & $\begin{array}{l}\text { All topics are Important and } \\
\text { Independent }\end{array}$ & $\begin{array}{l}\text { Can revise and reinforce contents with questions } \\
\text { and answers at own speed. }\end{array}$ \\
\hline Road Safety & Inverse Teaching & $\begin{array}{l}\text { Go deeper into a subject. } \\
\text { Homogenize students. }\end{array}$ \\
\hline Proteotics Problems & Many logic problems & Explain steps in sequence. \\
\hline All & & $\begin{array}{l}\text { Reinforce master classes and presentations. } \\
\text { Lab guide. } \\
\text { Change medium (paper to interactive video). }\end{array}$ \\
\hline
\end{tabular}

Each teacher emphasized the part of the tool that fitted in with his teaching objectives, method, material or student follow-up. InterPLAY gave clear evidence of its didactic riches in the different contributions. Some teachers highlighted the improved student follow-up since they can incorporate reinforcement-questions to get a rapid feedback and also reinforce contents, including links to specific details that can be seen as often as necessary. It also facilitates individual learning rates and thus homogenizes the students. In short, InterPLAY can be used in all the subjects with diverse and complementary aims.

\subsubsection{Advantages and disadvantages}

The advantages and disadvantages indicated by the teachers are analyzed in this section. We created three blocks with two categories in each one: the first block includes teaching reasons, plus student evaluation and follow-up. The second block refers to InterPLAY's use and characteristics, while the third deals with technical reasons and preparation. 
These categories allow us to present a comparative study of the advantages and disadvantages, as shown in Table 2, and evaluate their weight in each category to palliate the disadvantages as far as possible.

The advantages predominate in the results of the first block, i.e. the tool's "teaching value" for promoting student autonomy, motivation, interactivity and follow-up in that it assists self-evaluation, reinforces contents and favours feedback. Only one disadvantage is indicated, which was not directly derived from the tool, which refers to the teachers' ability to design a video for this purpose, which is a disadvantage. .

The second block refers to the tool's "use characteristics". In general, the advantages also predominate here, in fact, only advantages were indicated in the characteristics, while in its use most indicated that it is easy to design. Only two teachers thought it was complex to use (as a disadvantage) and tutorials were given to solve this question.

In the third "technical reasons and preparation" block, advantages and disadvantages are more balanced. Approximately $40 \%$ of the teachers thought having specific videos and material available was a disadvantage for applying InterPLAY as regards technical reasons and saw the preparation and editing time as an inconvenience. In general we understood these contributions, but we have to say that any well designed teaching material that satisfies pedagogic criteria requires an effort and dedication, so that this disadvantage cannot be directly applied to the tool.

Table 2. Advantages and disadvantages of implementing InterPLAY.

\begin{tabular}{|c|c|c|}
\hline Categorías & Advantages & Disadvantages \\
\hline \multirow[t]{4}{*}{$\begin{array}{l}\text { Bl. Teaching } \\
\text { Reasons }\end{array}$} & $\begin{array}{l}\text { Interactive videos with high } \\
\text { teaching value }\end{array}$ & \multirow[t]{4}{*}{$\begin{array}{l}\text { Designing a video for teaching } \\
\text { aims. }\end{array}$} \\
\hline & Helps motivation & \\
\hline & Student Autonomy & \\
\hline & $\begin{array}{l}\text { Sequencer of contents and learning } \\
\text { speeds }\end{array}$ & \\
\hline \multirow{3}{*}{$\begin{array}{l}\text { B.I. Follow-up and } \\
\text { Evaluation }\end{array}$} & Means of evaluation & \\
\hline & $\begin{array}{l}\text { Including instructions in the } \\
\text { material helps student follow-up. }\end{array}$ & \\
\hline & Reinforcement questions & \\
\hline \multirow{2}{*}{$\begin{array}{l}\text { B.2. Use of } \\
\text { InterPLAY }\end{array}$} & Easy to use, practical and simple. & Complex \\
\hline & Easy to move around the video. & $\begin{array}{l}\text { Needs a lot of practice to get the } \\
\text { best use out of it. }\end{array}$ \\
\hline \multirow{3}{*}{$\begin{array}{l}\text { B.2. InterPLAY } \\
\text { Characteristics }\end{array}$} & Easy to obtain extra contents & \\
\hline & Sub-title options & \\
\hline & Immerse a video in another video & \\
\hline \multirow{3}{*}{$\begin{array}{l}\text { B.3. Technical } \\
\text { Reasons }\end{array}$} & Work from Windows or Mac. & Use it with your own videos. \\
\hline & Easy to update texts in videos & $\begin{array}{l}\text { Needs basic videos to apply } \\
\text { system. }\end{array}$ \\
\hline & $\begin{array}{l}\text { Contents can be edited and } \\
\text { included in diverse video layers. }\end{array}$ & $\begin{array}{l}\text { Find specific videos useful for } \\
\text { specific tasks in the subject. }\end{array}$ \\
\hline \multirow[t]{3}{*}{ B.3. Preparation } & Identifies objectives & $\begin{array}{l}\text { Pre-view all the material to be } \\
\text { included in the video. }\end{array}$ \\
\hline & $\begin{array}{l}\text { Create "timeless" teaching } \\
\text { materials. }\end{array}$ & Work of organizing the information. \\
\hline & Clearly structured material. & Editing time: assembly. \\
\hline
\end{tabular}




\subsection{Analysis of closed questions}

The closed part of the questionnaire consisted of three questions on the 5-level Likert scale from zero to very high to evaluate the tool's different functions.

- Questions and answers: videos can be stopped to ask questions with options to be answered directly or accede to other materials for an answer. Nested questions can also be asked according to whether or not the first is answered correctly.

- Links to other resources: links can be made to other online contents in the form of PDF files, images, other web pages, etc. during video reproduction or during an interactive pause.

- Viewing menu: links can be made from the answer options to viewing the video itself, which makes it possible to generate menus for the student to decide the video section he wishes to see.

- Learning levels: the teacher can generate contents at different levels for the student to select interactively the one he wishes to follow.

- Contents index: contents blocks can be marked in the video which are automatically listed in the index for access at any time, either to continue with the video or revise concepts.

- Autonomy (learning speeds): the teacher himself can generate interactive material from a web editor and set the pace he wants the students to follow.

- Contents updating: as this software layer is superimposed on the audiovisual, all the contents introduced can be later updated to make the most use of the audiovisual.

- Add messages: reinforcement or feedback messages can be sent to the student either to answer questions by marking an answer or during the video reproduction.

- Embed web contents: this characteristic allows embedding contents from other web pages into the audiovisual. It does not provide a link but shows the page on the screen so that the student can interact with it.

- Generate sub-titles: sub-titles can be generated in three languages selected from a wide range, either manually or by synchronizing a text or auto-transcription of the audio.

- An analysis was made of the interest for the student's learning (Questions 1 ), for the teacher (Question 2) and the degree of difficulty of using the system (Question 3). The results are given in the percentages obtained in each level of the Likert scale shown by means of a graph for each question.

\subsubsection{Interest for students}

The results for most functions were generally high (Level 4: High and Level 5: Very High), as can be seen in Figure 2. The over $60 \%$ of Level 5 highlights the high interest for the students in having questions and answers, a contents index and a viewing menu. These three applications organize the contents and help interactivity. They also appreciate the fact that students can choose their own learning speed.

As can be seen in Figure 2, what teachers most appreciate from the students' point of view is the fact that they can ask reinforcement or self-evaluation questions on the material viewed, make links to other additional contents to improve understanding, generate menus for individual and autonomous learning, and all of this can be done interactively. 


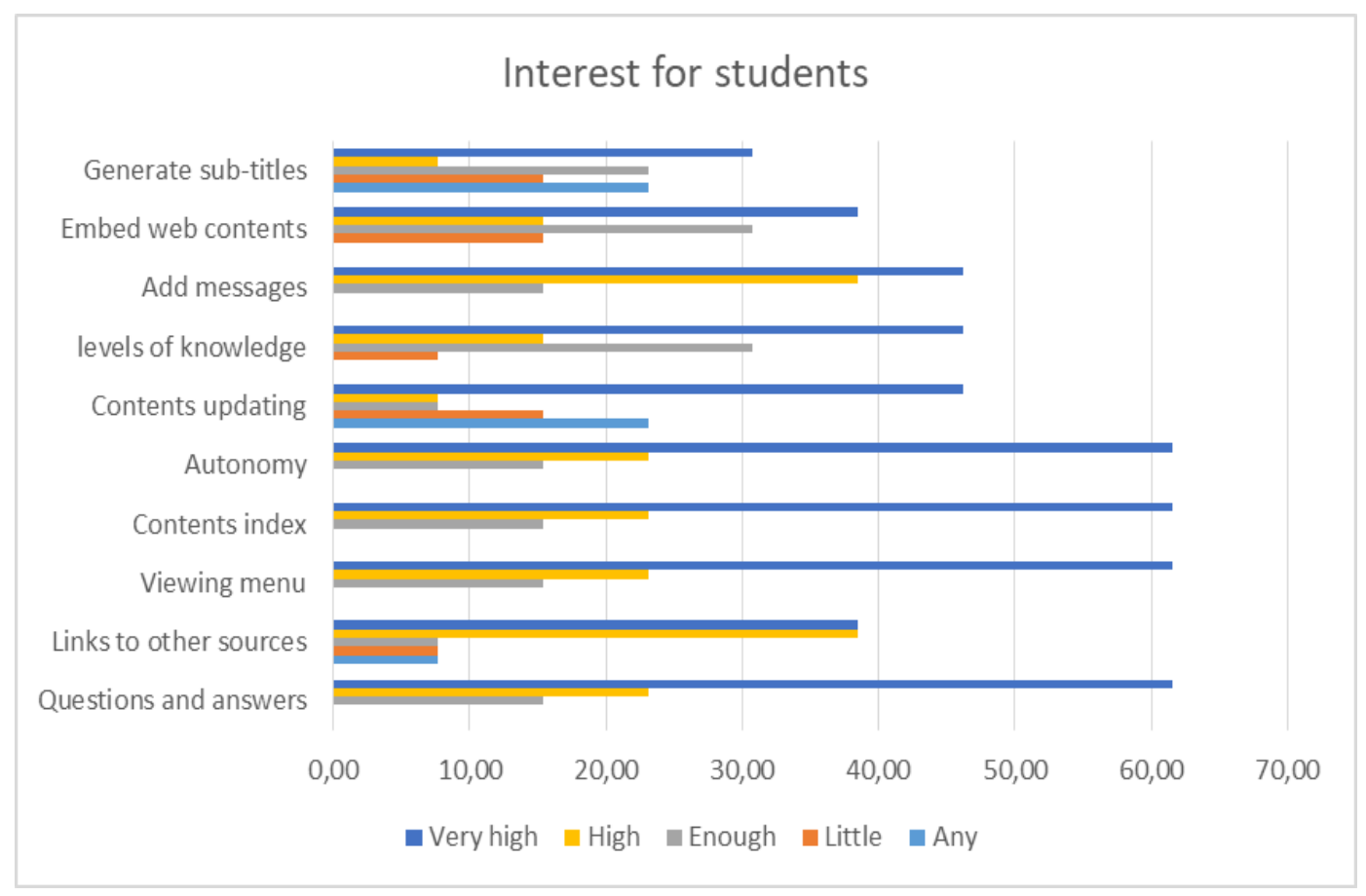

Figure 2. Interest for the student.

\subsubsection{Interest for the teacher}

As can be seen in Figure 3, the function teachers most value is that they can update contents by means of the tool without the need to remake a video and thus save time and effort in making audiovisuals for their students. They also positively value other functions with regard to content interactivity, on being able to ask questions and give answers, add feedback messages, link to other contents to reinforce learning, and update the video independently when necessary.

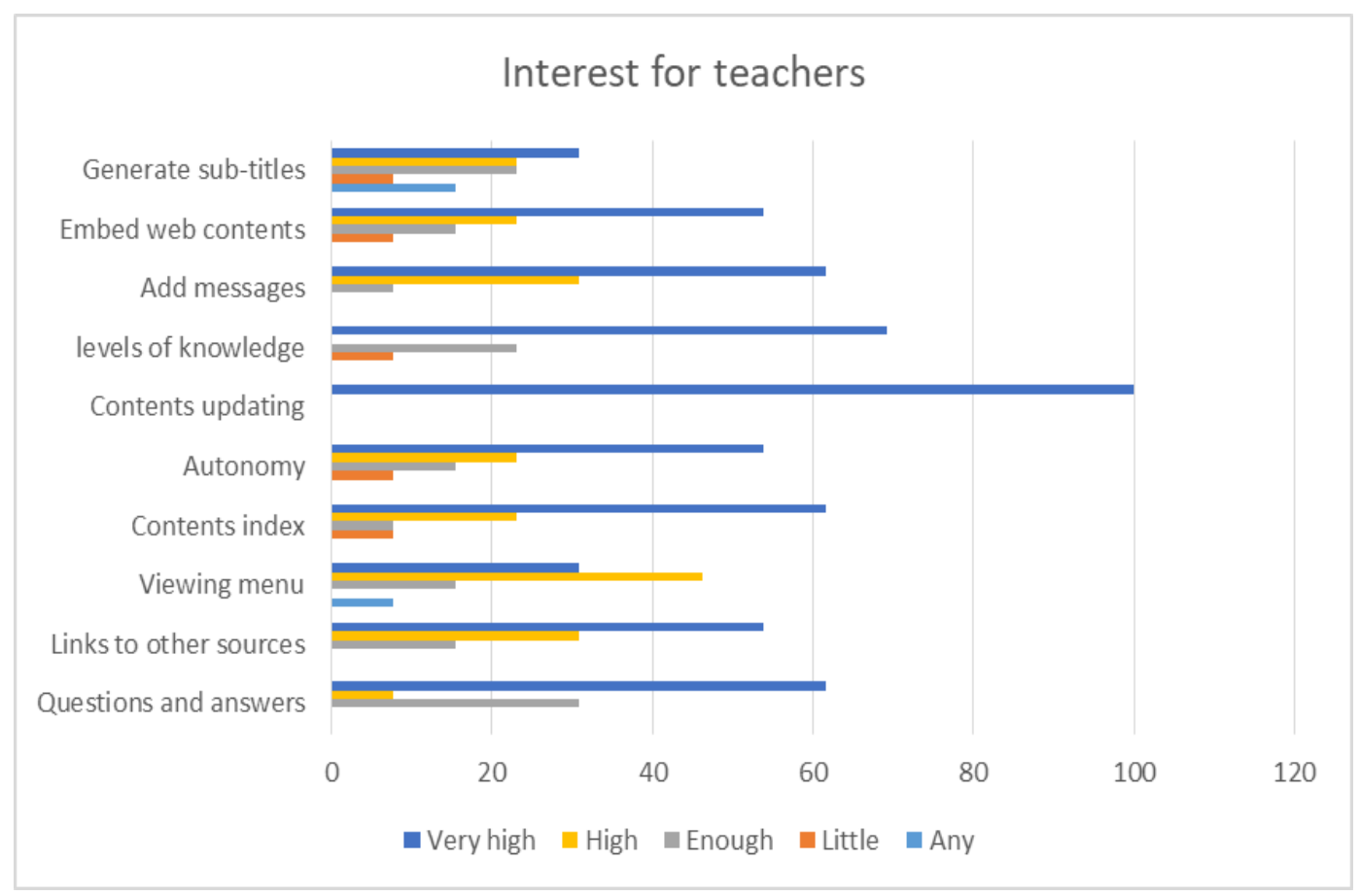

Figure 3. Interest for the teacher. 


\subsubsection{Difficulty of application}

According to Figure 4, teachers consider it easy to implement the InterPLAY tool. The functions most valued in the previous questions from both the teachers and students' point of view include: menus and contents indexes, being able to ask and answer questions, add feedback messages, generate learning speeds, make links and embed online contents.

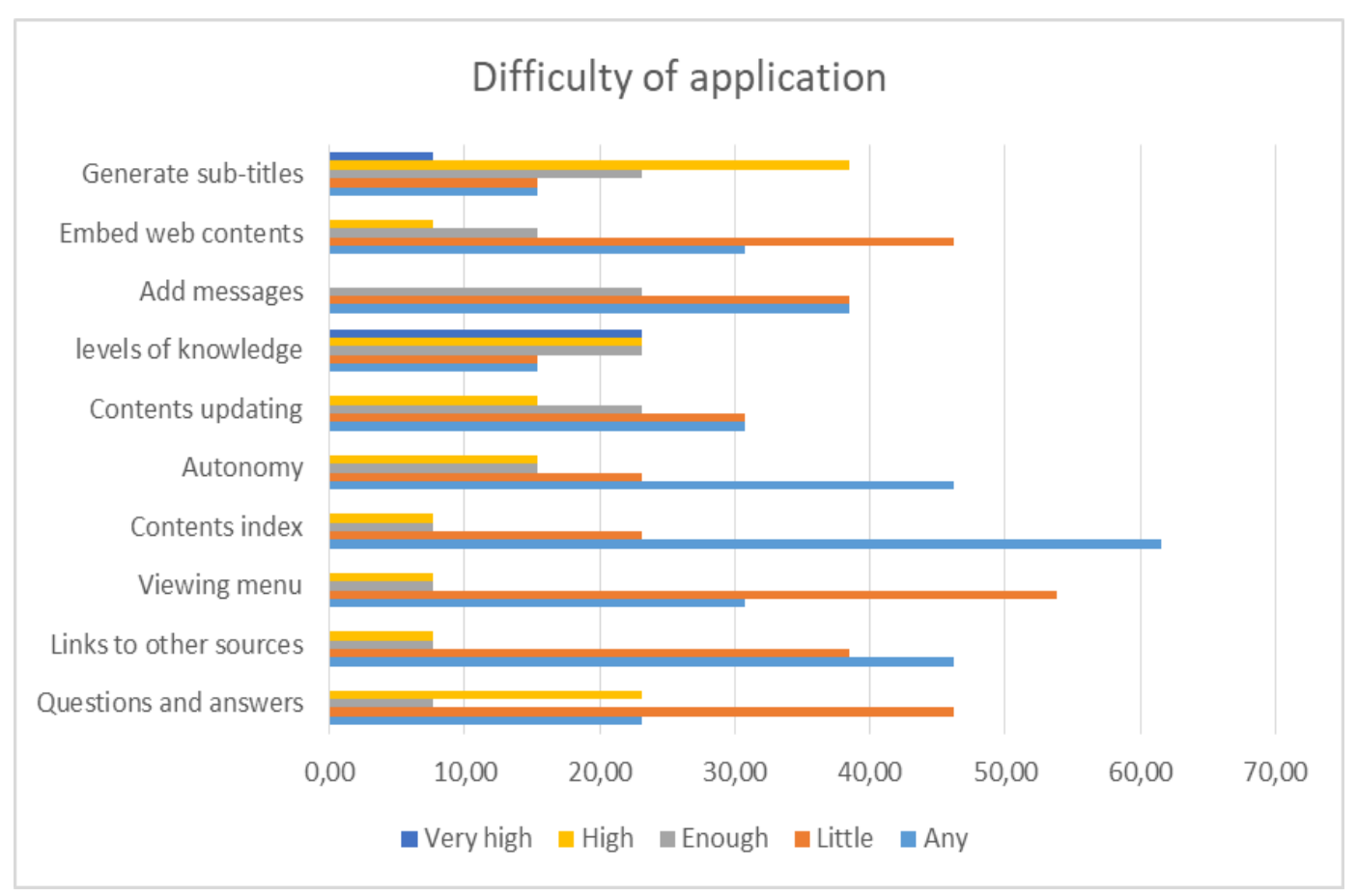

Figure 4. Application difficulties.

\section{CONCLUSIONS}

We can thus conclude that the interPLAY tool earned a positive evaluation. Even though the teachers have to dedicate a certain amount of time to preparing the system, they were able to make good use of its possibilities for deep learning of contents, understanding key concepts, motivating students, understanding the contents dealt with, and making the maximum use of the time spent in generating audiovisuals. As they themselves have pointed out, InterPLAY can be used in all subjects for simultaneously diverse and complementary aims.

\section{REFERENCES}

[1] BARTOLOME, A. Video Digital y Comunicación. Madrid. Síntesis. (2008).

[2] SOTOS SERRANO, M. Las preguntas en el aula. Análisis de la interacción educativa. Disponible en https://previa.uclm.es/ab/educacion/ensayos/pdf/revista16/16_16.pdf

[3] CABERO ALMENARA, J. (Coord.). Nuevas Tecnologías Aplicadas a la Educación. Madrid, Mc Graw Hill (2007)

[4] UNIVERSIDAD POLITÉCNICA DE VALENCIA Elementos motivadores incorporados en los Polimedias plus, vídeos didácticos y screencast para aumentar y mejorar el aprendizaje del estudiante. http://ocs.editorial.upv.es/index.php/INRED/INRED2017/paper/viewFile/6825/2678. Pdf [Consulta: 22 de abril 2020] 